\title{
Synthesis of 4,5-Benzotropone $\pi$-Complexes of Iron, Rhodium and Iridium and Their Potential Use in Catalytic Borrowing Hydrogen Reactions.
}

\author{
Takuya Kodama, ${ }^{\text {a,b }}$ Yuki Kawashima, ${ }^{\text {a }}$ Zhirong Deng ${ }^{\mathrm{a}}$ and Mamoru Tobisu*a,b \\ ${ }^{a}$ Department of Applied Chemistry, Graduate School of Engineering, Osaka University, Suita, Osaka 565-0871, Japan. E- \\ mail: tobisu@chem.eng.osaka-u.ac.jp
}

${ }^{b}$ Innovative Catalysis Science Division, Institute for Open and Transdisciplinary Research Initiatives (OTRI), Osaka University.

\begin{abstract}
The synthesis of rhodium, iridium, and iron $\pi$-complexes bearing 4,5benzotropone ligands are reported. X-ray crystallographic analyses revealed that a tropone core coordinates to a metal center in a $\eta^{4}$ manner with a tub-form geometry. Some of the benzotropone $\pi$-complexes exhibited catalytic activity for the $N$ alkylation of aniline via borrowing hydrogen.
\end{abstract}

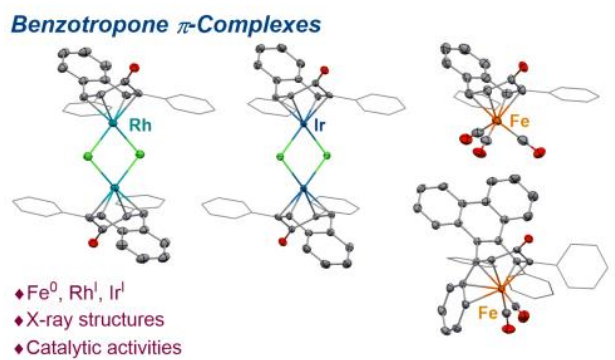

Since it was first synthesized in the early 1950s, ${ }^{1}$ cyclohepta-2,4,6-trien-1-one, or tropone, has played a prominent role in the development of non-benzenoid aromatic compounds. ${ }^{2}$ In the field of organometallic chemistry, the formation of metal complexes with tropones has been the subject of intense studies, and both $\sigma$ - and $\pi$-complexes with various metals have been reported. For example, tropone forms a $\sigma$-type $1: 1$ complex with $\mathrm{MCl}_{2}(\mathrm{M}=\mathrm{Mn}, \mathrm{Co}, \mathrm{Ni}, \mathrm{Cu}, \mathrm{Cd}, \mathrm{Hg}, \mathrm{Cd}),{ }^{3}$ whereas a $2: 1$ complex is generated with $\mathrm{ZnCl}_{2}{ }^{3}$ Concerning $\pi$ complexes, both $\eta^{4}$ - and $\eta^{6}$-complexes have been reported depending on the central metal being employed (Chart 1). For example, tropone forms $\eta^{4}$-complexes with rhodium(I) ${ }^{4}$ and group 8 metals such as iron $(0)^{5,6}$ and ruthenium(0), ${ }^{7}$ whereas $\eta^{6}$-complexes are favored with iron(II), ${ }^{8}$ ruthenium(II $)^{9}$ and group 6 metals, including chromium, molybdenum and tungsten. ${ }^{10}$ Despite the significant advancements that have occurred in the coordination chemistry of tropones, metal complexes of $\pi$-extended tropones have not been reported, except for chromium complexes ${ }^{11,12}$ of 4,5-[b]furanotropone and 4,5-[b]thienotropone and an iron complex ${ }^{13}$ of 2,3-benzotropone. Embedding a fused aromatic ring into a $\pi$-ligand stabilizes a complex with a lower hapticity, as represented by indenyl ligands, ${ }^{14}$ which frequently leads to an increase in catalytic activity by providing a vacant coordination site on demand.

\section{Chart 1. $\pi$-Complexes of Tropones.}

(a) Reported mononuclear tropone $\pi$-complexes

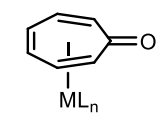

$\eta^{4}: \mathrm{Fe}^{0}, \mathrm{Ru}^{0}, \mathrm{Rh}^{1}$

$\eta^{6}: \mathrm{Fe}^{\mathrm{II}}, \mathrm{Ru}{ }^{\prime \prime}, \mathrm{Co}^{\prime}$

$\mathrm{Cr}^{0}, \mathrm{Mo}^{\circ}, \mathrm{W}^{0}$

(b) This work

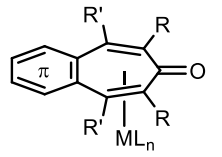

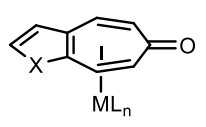

$\eta^{6}: \mathrm{Cr}^{0}$

Limited to heterocycle-

annulated tropones

$\eta^{4}: \mathrm{Fe}^{0}, \mathrm{Rh}^{1}, \mathrm{Ir}^{\prime}$

-X-ray structures

- Catalytic activities

Herein we report on the synthesis and characterization of rhodium, iridium and iron complexes ligated with 7H-benzo[7]annulen7-one (4,5-benzotropone) $)^{15}$ derivatives, the molecular structures of which were determined by X-ray crystallography. Moreover, some of the tropone complexes were found to catalyze the $N$-alkylation of aniline with benzyl alcohol via a borrowing hydrogen mechanism. 
Chart 2. Tropone Ligands Used in This Study.

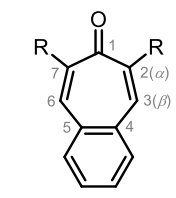

1a $(\mathrm{R}=\mathrm{Ph})$

1b $\left(\mathrm{R}=p-\mathrm{OMeC}_{6} \mathrm{H}_{4}\right)$

$1 c\left(\mathrm{R}=p-\mathrm{CF}_{3} \mathrm{C}_{6} \mathrm{H}_{4}\right)$

1d $\left(\mathrm{R}=\mathrm{CO}_{2} \mathrm{Me}\right)$

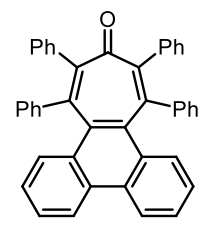

2

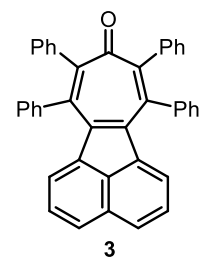

3

We focused on the use of multi-substituted 4,5-benzotropone derivatives 1-3 (Chart 2) as a ligand for transition metals to avoid undesired reactions at the tropone core ${ }^{5 c, 10 c, 16}$ when such complexes are used in catalytic reactions. Compounds 1 can readily be synthesized via the Knoevenagel condensation of $o$-phthalaldehyde and the corresponding ketone. ${ }^{17}$ More $\pi$-extended tropones 2 and 3 are accessible by Diels-Alder reactions of diphenylcyclopropenone and the corresponding cyclopentadienone derivative. ${ }^{18,19}$

Based on the synthetic procedure used for preparing a rhodium complex bearing a tetraphenylcyclopentadienone ligand ${ }^{20}$ the $2,7-$ disubstituted-4,5-benzotropone derivatives 1a-1d were reacted with $\left[\mathrm{Rh}\left(\mathrm{CH}_{2} \mathrm{CH}_{2}\right)_{2} \mathrm{Cl}\right]_{2}$ in refluxing benzene to form the dimeric rhodium complexes $\mathbf{4 a - 4 d}$ in 47-85\% yields (Scheme 2). Complex 4a could also be synthesized by reacting $\mathrm{RhCl}_{3}$ and $\mathbf{1 a}$ in methanol, although the product yield was slightly lower (55\%, see electronic supplementary information (SI)). The iridium analogue $\mathbf{5 a}$ was obtained by a ligand exchange reaction using $\left.\left[\mathrm{Ir}_{(\mathrm{CH}} \mathrm{CH}_{2}\right)_{2} \mathrm{Cl}\right]_{2}$ and $\mathbf{1 a}$ in $66 \%$ yield. ${ }^{1} \mathrm{H}-\mathrm{NMR}$ spectra of $4 \mathbf{a}$ and $\mathbf{5 a}$ in $\mathrm{CDCl}_{3}$ displayed an up-field shift in $\beta$-protons compared to those in the parent $1 \mathbf{a}$ from $7.73 \mathrm{ppm}$ to $5.05 \mathrm{ppm}$ for $\mathbf{4 a}$ and to $5.47 \mathrm{ppm}$ for $\mathbf{5 a}$, respectively, suggesting that the alkene moiety of $\mathbf{1 a}$ is bound to the metal center. Single crystals of $\mathbf{4 a}$ and $\mathbf{5 a}$ suitable for X-ray crystallographic analysis were obtained by recrystallization from a $\mathrm{CHCl}_{3} /$ hexane solution. The ORTEP drawings of $\mathbf{4 a}$, and $\mathbf{5 a}$ are shown in Scheme 1 (cf. Figure. S3 in the SI) and Fig. S5 in the SI, respectively, and selected structural parameters are summarized in Table 1. These data revealed that the 4,5-benzotropone coordinates to the metal center in a $\eta^{4}$ manner through the carbons at the 2,4,6 and 7 positions, resulting in the formation of a tub-form geometry. The seven-membered rings of the ligated 1a in 4a and 5a were bent by 44-49 degrees (Table 1) whereas the conformation of the 4,5-benzotropone skeleton of the parent 1a is planar. ${ }^{21}$ Both $4 \mathbf{a}$ and $\mathbf{5 a}$ possess a $C_{2 \mathrm{~h}}$ symmetry in which two benzotropone cores are ligated in opposite directions. The distance for the $\mathrm{C} 2-\mathrm{C} 3$ and $\mathrm{C} 6-\mathrm{C} 7$ double bonds in the iridium complex $\mathbf{5 a}$ were slightly longer than that of the rhodium analogue $\mathbf{4 a}$, indicating a stronger back donation from iridium than from rhodium. ${ }^{22}$ In support of this conclusion, the calculated Wiberg bond indices (WBIs, Table 2 ) $^{23}$ for the $\mathrm{C} 2-\mathrm{C} 3$ and C6-C7 double bonds in 5a (1.22) were smaller than that for the rhodium complex 4a (1.30). Conversely, the WBIs for C2-Ir (0.515) and C3-Ir (0.598) of 5a were larger than those for C2-Rh (0.409) and C3-Rh (0.491) in 4a.

\section{Scheme 2. Synthesis of Complexes 4-7. ${ }^{a}$}

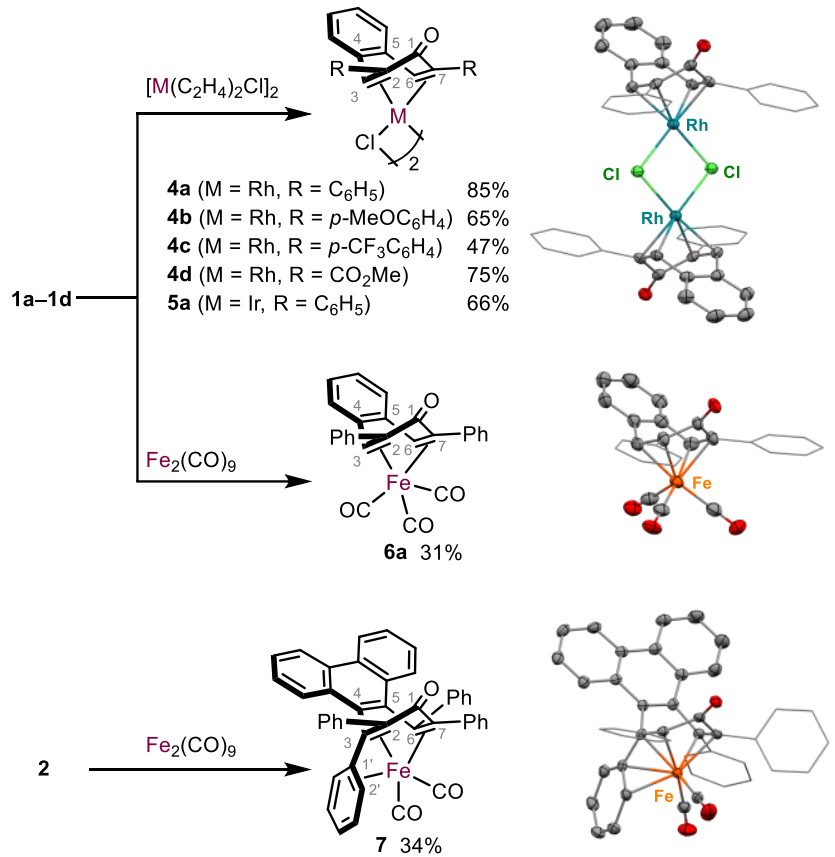

${ }^{a}$ ORTEP drawings of $\mathbf{4 a}, \mathbf{6 a}$, and $\mathbf{7}$ were plotted at the $50 \%$ probability levels. Hydrogen atoms were omitted for clarity. Phenyl groups that do not directly coordinate to the metals are depicted as wireframe forms. 
Table 1. Selected Bond Lengths (̊̊) and Angles (deg.) for 4a, 5a, 6a, and 7. ${ }^{a}$

$\begin{array}{lcccc} & \mathbf{4 a} & \mathbf{5 a} & \mathbf{6 a} & \mathbf{7} \\ \mathrm{C} 2-\mathrm{C} 3 & 1.426(5) & 1.446(6) & 1.419(5) & 1.464(4) \\ \mathrm{C} 6-\mathrm{C} 7 & 1.417(6) & 1.433(6) & 1.431(6) & 1.429(4) \\ \text { C1'-C2' } & & & & 1.431(4) \\ \text { C2-M } & 2.135(3) & 2.108(6) & 2.169(3) & 2.086(3) \\ \text { C3-M } & 2.130(3) & 2.120(5) & 2.135(3) & 2.029(3) \\ \text { C6-M } & 2.133(4) & 2.115(4) & 2.135(4) & 2.228(3) \\ \text { C7-M } & 2.124(3) & 2.123(5) & 2.181(3) & 2.120(3) \\ \text { C1'-M } & & & & 2.137(3) \\ \text { C2'-M } & & & & 2.335(3) \\ \theta & 43.83 & 44.62 & 36.60 & 41.58 \\ \varphi & 45.15 & 49.00 & 49.81 & 57.23\end{array}$

${ }^{a} \theta$ and $\varphi$ are the bent angles between the meanplanes (C2-C3-C6-C7 and C1-C2-C7) and (C2-C3-C6-C7 and C3-C4-C5-C6), respectively.

Table 2. Wiberg Bond Indices.

$\begin{array}{lcrrr} & \mathbf{4 a} & \mathbf{5 a} & \mathbf{6 a} & \mathbf{7} \\ \mathrm{C} 2-\mathrm{C} 3 & 1.297 & 1.220 & 1.278 & 1.103 \\ \mathrm{C} 6-\mathrm{C} 7 & 1.297 & 1.220 & 1.278 & 1.304 \\ \text { C1'-C2' } & & & & 1.191 \\ \text { C2-M } & 0.409 & 0.515 & 0.321 & 0.450 \\ \text { C3-M } & 0.491 & 0.598 & 0.431 & 0.407 \\ \text { C6-M } & 0.491 & 0.598 & 0.431 & 0.335 \\ \text { C7-M } & 0.409 & 0.515 & 0.321 & 0.378 \\ \text { C1'-M } & & & & 0.205 \\ \text { C2'-M } & & & & 0.379\end{array}$

The benzotropone $\pi$-complex of iron was synthesized by following the synthetic method used to prepare the (tropone)Fe(CO) ${ }_{3}{ }^{5}$ Thus, the treatment of $\mathbf{1 a}$ with $\mathrm{Fe}_{2}(\mathrm{CO})_{9}$ in benzene at $55{ }^{\circ} \mathrm{C}$ for $1.5 \mathrm{~h}$ afforded the iron tricarbonyl complex $\mathbf{6 a}$ in $31 \%$ yield. ${ }^{1} \mathrm{H}$ NMR spectra of $\mathbf{6 a}$ in $\mathrm{CDCl}_{3}$ also displayed a significant up-field shift of the $\beta$-protons to $4.61 \mathrm{ppm}$. Attempts to synthesize rhodium and iridium complexes of $\pi$-extended 4,5-benzotropone derivatives $\mathbf{2}$ and $\mathbf{3}$, instead of $\mathbf{1}$, using the identical protocol were unsuccessful. On the other hand, the reaction of tropone 2 and $\mathrm{Fe}_{2}(\mathrm{CO})_{9}$ in benzene afforded the corresponding iron complex 7. The structures of the iron complexes $\mathbf{6 a}$ and 7 were unambiguously determined by X-ray crystallography (Scheme1). A $\left(2,3,6,7-\eta^{4}\right)$ - coordination with a ligated seven-membered ring having a bent structure was observed for iron complexes $6 \mathbf{a}$ and 7 , as in the cases for the corresponding rhodium and iridium complexes (i.e., $\mathbf{4 a}, \mathbf{4 d}$ and $\mathbf{5 a})$. This type of $\left(2,3,6,7-\eta^{4}\right)$-coordination is different from that for the iron complex bearing a parent tropone as a ligand, which exclusively coordinates in a $\left(2,3,4,5-\eta^{4}\right)$ manner. ${ }^{4,5 b}$ An interesting feature of complex 7 is that one of the carbonyl ligands is substituted by a phenyl group at the 3 position, which coordinates to the iron center in a $\eta^{2}$ manner (Scheme 1). The C2-C3 bond length of 7 (1.46 $\AA$ ) is slightly longer than that of $6 \mathbf{a}(1.42-1.43 \AA$ ), while the distances between C2-C3 and the iron center (1.92 $\AA$, see Chart S1 and Table S1 in the SI) in 7 are shorter than those for $6 \mathbf{a}$ ( $2.03 \AA$ ), likely due to the additional coordination of a phenyl group. The WBI for the C2-C3 bond (1.10) of 7 indicated a more single bond-like character compared to $6 \mathrm{a}$ (WBI for C2-C3: 1.28). The relatively long distance between the C1'-C2' double bond and the iron center $(2.07 \AA)$ indicates that the phenyl group at the 3 -position is weakly coordinating and could serve as a hemilabile ligand ${ }^{24}$ that would generate a vacant coordination site for promoting catalysis.

Since the structural and coordination features of 4-7 are similar to those of cyclopentadienone ligands, such as Shvo type catalysts, ${ }^{25}$ we hypothesized that the benzotropone complexes 4-7 could serve as a catalyst for borrowing hydrogen reactions. ${ }^{26}$ Thus, we examined the reaction of benzyl alcohol and aniline in the presence of 5-10 mol\% of 4-7 at $160{ }^{\circ} \mathrm{C}$ for $16 \mathrm{~h}$. The use of the rhodium complex $4 \mathbf{a}$ as a catalyst provided the desired $N$-benzylation product in $74 \%$ yield (Entry 1 ). Whereas no product was formed when methoxy groups were introduced at the $p$-positions of the pendant phenyl groups in $\mathbf{4 b}$ (Entry 2), the electron deficient 4 -trifluoromethyl analogue 4c (Entry 3) and the ester derivative 4d (Entry 4) afforded the desired product in comparable yield. The iridium analogue 5a (Entry 5) also showed catalytic activity but the yield was only 15\%. Iron complexes 6 a and 7 showed no catalytic activities for this reaction (Entries 6 and 7).

In conclusion, rhodium, iridium and iron complexes ligated with 4,5-benzotropone derivatives were synthesized and characterized. X-ray crystallographic analysis and the findings revealed that these complexes have a tub-shape conformation with $\left(2,3,6,7-\eta^{4}\right)$ coordination. Some of the rhodium complexes catalyzed $N$-alkylation reactions of aniline with benzyl alcohol via borrowing hydrogen. Further investigations of the reaction mechanism and applications to other catalytic transformation using benzotropone complexes are now underway in our laboratory. 
Table 1. Application of Borrowing-Hydrogen Reactions.

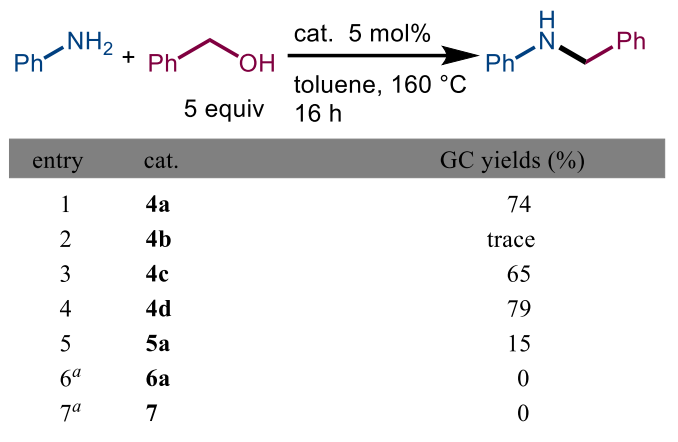

${ }^{a} 10 \mathrm{~mol} \%$ was used as a catalyst.

\section{Supporting Information}

Experimental procedures and supporting characterization data and spectra (PDF)

Compound 1d, 2, 4a, 4d, 5a, 6a, 7 crystal structure (CIF)

\section{Author Information}

Corresponding Author

Mamoru Tobisu - Department of Applied Chemistry, Graduate School of Engineering, Osaka University, Suita, Osaka 5650871, Japan; Innovative Catalysis Science Division, Institute for Open and Transdisciplinary Research Initiatives (OTRI), Osaka University; http://orcid.org/0000-0002-8415-2225; E-mail: tobisu@chem.eng.osaka-u.ac.jp

\section{Authors}

Takuya Kodama - Department of Applied Chemistry, Graduate School of Engineering, Osaka University, Suita, Osaka 5650871, Japan; Innovative Catalysis Science Division, Institute for Open and Transdisciplinary Research Initiatives (OTRI), Osaka University; http://orcid.org/0000-0001-8275-2393

Yuki Kawashima - Department of Applied Chemistry, Graduate School of Engineering, Osaka University, Suita, Osaka 5650871, Japan

Zhirong Deng - Department of Applied Chemistry, Graduate School of Engineering, Osaka University, Suita, Osaka 5650871, Japan

\section{Notes}

The authors declare no competing financial interest.

\section{Acknowledgment}

This work was supported by a Grant-in-Aid for Early-Career Scientists (19K15564) and Scientific Research on Innovative Area "Hybrid Catalysis" (20H04818) from MEXT, Japan. The authors wish to thank Dr. Sato (Rigaku Corporation) for the single crystal X-ray crystallographic analysis of $\mathbf{7}$ and Dr. Iwamoto (Osaka University) for helpful discussions. We also wish to thank the Instrumental Analysis Center, Faculty of Engineering, Osaka University, for their assistance with HRMS and elemental analysis.

\section{References}

(1) (a) Dauben, H. J. Jr.; Ringold, H. J. SYNTHESIS OF TROPONE. J. Am. Chem. Soc. 1951, 73, 876; (b) Doering, W. E.; Detert, F. L. CYCLOHEPTATRIENYLIUM OXIDE. J. Am. Chem. Soc. 1951, 73, 876-877; (c) Nozoe, T.; Mukai, T.; Takase, K.; Nagase, T. Tropone and Its Derivatives. VII. On Tropone (Cycloheptatrienone). Proc. Jpn. Acad. 1952, 28, 477-482.

(2) Selected reviews on tropones, see: (a) Pauson, P. L.Tropones and Tropolones. Chem. Rev. 1955, 55, 9-136; (b) Nozoe, T. RECENT ADVANCES IN THE CHEMISTRY OF TROPONOIDS AND RELATED COMPOUNDS IN JAPAN. Pure. Appl. Chem. 1971, 28, 239-280; (c) Pietra, F. Seven-membered conjugated carbo- and heterocyclic compounds and their homoconjugated analogs and metal complexes. Synthesis, biosynthesis, structure, and reactivity. Chem. Rev. 1973, 73, 293-364; (d) Pietra, F. Revival of troponoid chemistry. Acc. Chem. Res. 1979, 12, 132-138.

(3) Asao, T.; Kikuchi, Y. THE PREPARATION OF SOME TROPONE COMPLEXES. Chem. Lett. 1972, 1, $413-416$.

(4) Nikanorov, V. A.; Storozhev, T. V.; Novikov, S. G.; Sergeev, S. V.; Zverev, D. V. Redox troponization of $\left(\eta^{5}\right.$-cyclopentadienyl) $\left(\eta^{4}-4\right.$-enthyl4-exo-trichloromethylcyclohexa-2,5-dien-1-one)rhodium as a novel approach to the synthesis of metal-coordinated nonbenzenoid aromatics of the tropone seriesas a novel approach to the synthesis of metal-coordinated nonbenzenoid aromatics of the tropone series. Russ. Chem. Bull. 1998, 47, 1224-1225.

(5) Selected examples of tropone iron tricarbonyl, see: (a) King, R. B. Organometallic Chemistry of the Transition Metals. V. New Iron Carbonyl Complexes of Cycloöcctatriene Derivatives. Inorg. Chem. 1963, 2, 807-810; (b) Dodge, R. P. The Crystal and Molecular Structure of Tropone 
Iron Tricarbonyl. J. Am. Chem. Soc. 1964, 86, 5429-5431; (c) Hunt, D. F.; Farrant, G. C.; Rodeheaver, G. T. Chemistry of (cycloheptatrienone)tricarbonyliron and (cycloheptadienone)tricarbonyliron in highly acidic media. J. Organomet. Chem. 1972, 38, 349-365; (d) Morita, N.; Asao, T.; Tajiri, A.; Sotokawa H.; Hatano, M. THE SYNTHESES OF IRON CARBONYL COMPLEXES OF 2-SUBSTITUTED TROPONES. Chem. Lett. 1985, 14, 1879-1882.

(6) A tropone iron tricarbonyl was first prepared from acetylene and $\mathrm{Fe}_{2}(\mathrm{CO})_{9}$, see Weiss, E.; Hubel, W. Über Organometall-Komplexe, XI. Zur Kenntnis von Tropon-eisentricarbonyl. Chem. Ber. 1962, 95, 1179-1185.

(7) (a) Domingos, A. J. P.; Johnson, B. F. G.; Lewis, J. Ligand displacement reactions of 1,5-cylooctadienetricarbonylruthenium. J. Organomet. Chem. 1973, 49, C33-C34; (b) Domingos, A. J. P.; Johnson, B. F. G.; Lewis, J. Reactivity of co-ordinated ligands. Substitution reactions of tricarbonyl ( $\eta$-cycloocta-1,5-diene)ruthenium. J. Chem. Soc., Dalton Trans. 1975, 2288-2291.

(8) Sutherland, R. G.; Piorko, A.; Lee C. C. (Tropone)- and (tropothione)iron complexes from ring expansion reactions. Organometallics 1984, 3 , $331-332$.

(9) Kimura, M.; Morita, M. Isolation of ( $\eta^{5}$-Cyclopentadienyl)(1,2,3,4,5- $\eta^{6}$-exo-methoxy-7-oxo-2,4-cycloheptadienyl)ruthenium(II) as a Key Intermediate for the Selective Hydrogen/deuterium Exchange on Its Coordinated Tropone Moiety by KOH/CD ${ }_{3} \mathrm{OD}$. Bull. Chem. Soc. Jpn. 1993, 66, 3120-3123.

(10) (a) Pauson, P. L.; Todd, K. H. Cycloheptatriene and Tropylium Metal Complexes. Part VI. Tropone and Alkoxycycloheptatriene Complexes of Tricarbonylchromium.

J. Chem. Soc. C, 1970, 2315-2318; (b) Lal, K.; Leckey, N. T.; Watts, W. E. The relative strengths of the $\mathrm{Cr}(\mathrm{CO})_{3}, \mathrm{Mo}(\mathrm{CO})_{3}$, and W(CO) ${ }_{3}$ complexes of tropone. J. Organomet. Chem. 1983, 258, 205-208. (c) Morkan, I. A.; Morkan, A. U. Cycloaddition Reactions of ( $\square{ }^{6}$-Tropone)tricarbonylmetal(0) Complexes of Group 6 Metals with Alkynes. Collect. Czech. Chem. Commun. 2002, 67, 1635-1646.

(11) (a) Borai, M. E.; Guilard, R.; Fournari, P. Etude de la complexation de systemes arenotroponiques par le chrome hexacarbonyle. J. Organomet. Chem. 1978, 148, 277-284; (b) Dusausoy, Y.; Protas, J. 3a-4:8-8a- $\eta$-(Diméthyl-5,7 cyclohepta[b]furanone one-6) chrome tricarbonyle. Acta Cryst. 1978, B34, 1714-1716.

(12) 4,5-Benzotropone derivatives form $\eta^{6}$-complex with chromium at benzene core, see: Besançon, J.; Top, S.; Tirouflet, J.; Gautheron, B.; Dusausoy Y. Pseudoasymetrie dans la serie du benchrotrene I. Synthese des trois glycols ortho-substitues $(\mathrm{OC})_{3} \mathrm{CrC}_{6} \mathrm{H}_{4}\left(\mathrm{CHOHCH}_{3}\right)_{2}$. J. Organomet. Chem. 1975, 94, 35-46.

(13) Tajiri, A.; Morita, N.; Asao, T.; Hatano, M. Activation Energy of the Racemization of Optically Active Tricarbonyl(tropone)iron Complexes. Angew. Chem. Inet. Ed. 1985, 24, 329-330.

(14) (a) Rerek, M. E.; Ji, L.-N. Basolo, F. The indenyl ligand effect on the rate of substitution reactions of $\mathrm{Rh}\left(\eta-\mathrm{C}_{9} \mathrm{H}_{7}\right)(\mathrm{CO})_{2}$ and $\mathrm{Mn}\left(\eta\right.$ - $\left.\mathrm{C}_{9} \mathrm{H}_{7}\right)(\mathrm{CO})_{3}$. J. Chem. Soc., Chem. Commun. 1983, 19, 1208-1209; (b) Rerek, M. E.; Basolo, F. Kinetics and Mechanism of Substitution Reactions of $\eta^{5}$ Cyclopentadienyldicarbonylrhodium(I) Derivatives. Rate Enhancement of Associative Substitution in Cyclopentadienylmetal Compounds. J. Am. Chem. Soc. 1984, 106, 5908-5912; (c) Veiros, L. F. The Role of Haptotropic Shifts in Phosphine Addition to Tricarbonylmanganese Organometallic Complexes: The Indenyl Effect Revisited. Organometallics 2000, 19, 3127-3136; (d) Calhorda, M. J.; Romão, C. C.; Veiros, L. F. The Nature of the Indenyl Effect. Chem. Eur. J. 2002, 8, 868-875.

(15) Dastan, A.; Kilic, H.; Saracoglu, N. One hundred years of benzotropone chemistry. Beilstein J. Org. Chem. 2018, 14, 1120-1180.

(16) (a) Johnson, B. F. G.; Lewis, J.; McArdle, P.; Randall, G. L. P. Reactivity of co-ordinated ligands. Part XII. Some heptafulvene complexes of tricarbonyliron and their electrophilic reactions. J. Chem. Soc., Dalton Trans. 1972, 2076-2083; (b) Eisenstadt, A.; Guss, J. M.; Mason, R. The dimer of heptafulveneiron tricarbonyl. J. Organomet. Chem. 1974, 80, 245-256; (c) Eisenstadt A. Fluxional behaviour of protonated substituted troponeiron tricarbonyls. J. Organomet. Chem. 1975, 97, 443-451; (d) Franck-Neumann, M.; Martina, D. Reaction des diazoalcanes avec le complexe tropone-fer tricarbonyle: Une nouvelle synthese specifique d'homo-2,3 tropones. Tetrahedron Lett. 1975, 16, 1759-1762; (e) Gompper, R.; Reiser, W. 8.8-dimarcapto-heptafulvene. Tetrahedron Lett. 1976, 16, 1263-1264; (f) Eisenstadt, A. The reactivity of cycloheptadienyl-1-one iron tricarbonyl cation towards nucleophilic attack. J. Organomet. Chem. 1976, 113, 147-156; (g) Goldschmidt, Z.; Bakal, Y. The cycloaddition reaction of troponeirontricarbonyl and tetracyanoethylene. Tetrahedron Lett. 1976, 17, 1229-1232; (h) Goldschmidt, Z.; Antebi, S. A novel 1,3-diene- to $\sigma, \pi$-allyliron tricarbonyl dyotropic arrangement. Cycloaddition reactions of cycloheptatrieneiron tricarbonyl and diphenylketene. Tetrahedron Lett. 1976, 17, 271-274; (i) Franck-Neumann, M.; Cycloadditions de la tropone avec le cyclopentadiene : synthese d'un intermediaire potentiel par utilisation de complexe metallique. Tetrahedron Lett. 1977, 18, 2293-2296; (j) Goldschmidt, Z.; Antebi, S. Irontricarbonyl complexes of diaryl-heptafulvenes and sesquifulvalenes. The reaction of troponeiron tricarbonyl with diarylketenes. Tetrahedron Lett. 1978, 19, 1225-1228; (k) Franck-Neumann, M.; Brion, F.; Martina, D. Friedel-Crafts acylation of tropone-irontricarbonyl. Synthesis of $\beta$-thujaplicin and $\beta$-dolabrin. Tetrahedron Lett. 1978, 19, 5033-5036; (1) Cavazza, M.; Morganti, G.: Pietra, F. Synthesis of (7(alkylthio)- and 7-(arylthio)cycloheptatriene)tricarbonyliron and -hexacarbonyldiiron complexes. J. Org. Chem. 1980, 45, 2001-2004. (m) Ban, T.; Nagai, K.; Miyamoto, Y.; Harano, K.; Yasuda, M.; Kanematsu, K. Periselective cycloaddition of tricarbonyliron complexes of seven-membered unsaturated compounds with 1,2,4,5-tetrazine. Masking and activating effects of tricarbonyliron complexes. J. Org. Chem. 1982, 47, 110116; (n) Morita, N.; Asao, T. THE SYNTHESES OF HEXACARBONYL (TROPONE) DIIRON AND SEVERAL TRICARBONYLIRON COMPLEXES OF HEPTAFULVALENE. Chem. Lett. 1982, 11, 1575-1578; (o) Morita, N.; Asao, T.; Sotokawa, H.; Hatano, M.; Tajiri, A Synthesis and absolute configuration of optically pure tricarbonyl(2,4-cycloheptadienonium)iron tetrafluoroborate. J. Organomet. Chem. 1988, 339, C1-C4; (p) Coquerel, Y.; Deprés, J-P, Greene, A. E.; Philouze, C. Addition of organolithium compounds to tricarbonyl(tropone)iron complexes: experimental and structural studies. J. Organomet. Chem. 2002, 659, 176-185.

(17) (a) Thiele, J.; Schneider, J. Ueber Condensationsproducte des o-Phtalaldehyds. Justus Liebigs Ann. Chem. 1909, 369, 287-299; (b) Thiele, J; Weitz E. Über Kondensationsprodukte des o-Phthalaldehyds. Justus Liebigs Ann. Chem. 1910, 377, 1-22.

(18) (a) Sasaki, T.; Kanematsu, K.; Iizuka, K. Molecular Design by Cycloaddition Reactions. XXV. High Peri- and Regiospecificity of Phencyclone. J. Org. Chem. 1976, 41, 1105-1112; (b) Yang, X.; Miao, Q. Studies toward the Synthesis of Hepta-peri-heptabenzo-[7]circulene. Synlett 2016, 27, 2091-2094.

(19) Non-substituted derivative of $\mathbf{3}$ was reported as a highly polarized tropone; see Yamamoto, K.; Matsue, Y.; Murata, I. HIGHLY POLARIZED TROPONES. 9H-AZULENO[1,2,3-ij]NAPHTHALEN-9-ONE AND 8H-AZULENO[1,2,3-ij]NAPHTHALEN-8-ONE. Chem. Lett. 1981, 10, $1071-1074$.

(20) Bailey, N. A.; Jassal, V. S.; Vefghi, R.; White, C. The Chemistry of Tetraphenylcyclopentadienone Complexes of Ruthenium and Rhodium: the X-ray crystal structure of $\left[\mathrm{Ru}\left\{\eta^{5}-\mathrm{C}_{5} \mathrm{Ph}_{4} \mathrm{OC}(\mathrm{O}) \mathrm{CH}(\mathrm{OMe}) \mathrm{Ph}\right\}(\mathrm{CO})_{2} \mathrm{Cl}\right]$ J. Chem. Soc. Daltaon Trans. 1987, 11, $2815-2822$.

(21) Ibata, K.; Shimanouchi, H.; Sasada, Y. Structural Chemistry of the Benzotropone System. IV. The Crystal and Molecular Structure of 2,7Diphenyl-4,5-benzotropone. Acta Cryst. 1977, B33, 1129-1138. 
(22) Back Donation (a) Hou, C.; Jiang, J.; Zhang, S.; Wang, G.; Zhang, Z.; Ke, Z.; Zhao, C. Hydrogenation of Carbon Dioxide Using Half-Sandwich Cobalt, Rhodium, and Iridium Complexes: DFT Study on the Mechanism and Metal Effect. ACS Catal. 2014, 4, 2990-2997; (b)Sasakura, K.; Okamoto, K.; Sakaki, S; Ohe, K. The Reaction Pathway Leading to Dinuclear Rhodium and Iridium Complexes from Alkyne-Containing Bisphosphine Ligands. Bull. Chem. Soc. Jpn. 2020, 93, 794-798.

(23) Wiberg, K. B. Application of the pople-santry-segal CNDO method to the cyclopropylcarbinyl and cyclobutyl cation and to bicyclobutane. Tetrahedron, 1968, 24, 1083-1096.

(24) Selected reviews on hemilabile ligand, see: (a) Bader, A.; Lindner, E. Coordination chemistry and catalysis with hemilabile oxygen-phosphorus ligands. Coord. Chem. Rev. 1991, 108, 27-110; (b) Slone, C.S.; Weinberger, D.A.; Mirkin, C. A. The Transition Metal Coordination Chemistry of Hemilabile Ligands. Prog. Inorg. Chem. 1999, 48, 233-350; (c) Braunstein, P.; Naud, F. Hemilability of Hybrid Ligands and the Coordination Chemistry of Oxazoline-Based Systems. Angew. Chem. Int. Ed. 2001, 40, 680-699; (d) Bassetti, M. Kinetic Evaluation of Ligand Hemilability in Transition Metal Complexes. Eur. J. Inorg. Chem. 2006, 2006, 4473-4482; (e) Weng, Z.; Teo, S.; Hor T. S. A. Metal Unsaturation and Ligand Hemilability in Suzuki Coupling. Acc. Chem. Res. 2007, 40, 676-684; (f) Oliveri, C.G.; Ulmann, P.A.; Wiester, M. J.; Mirkin, C. A. Heteroligated Supramolecular Coordination Complexes Formed via the Halide-Induced Ligand Rearrangement Reaction. Acc. Chem. Res. 2008, 41, 1618-1629; (g) Weng, Z.; Teo, S.; Hor, T.S.A. Metal Unsaturation and Ligand Hemilability in Suzuki Coupling. Acc. Chem. Res. 2007 40, 676-684; (h) Adams, G. M.; Weller, A. S. POP-type ligands: Variable coordination and hemilabile behavior. Coord. Chem. Rev. 2018, 355, $150-172$.

(25) (a) Shvo, Y.; Czarkie, D.; Rahamim, Y. A new group of ruthenium complexes: structure and catalysis. J. Am. Chem. Soc. 1986, 108, 74007302; (b) Conley, B. L.; Pennington-Boggio, M. K.; Boz, E.; Williams, T. J. Discovery, Applications, and Catalytic Mechanisms of Shvo's Catalyst. Chem. Rev. 2010, 110, 2294-2312.

(26) Irrgang, T.; Kempe, R. 3d-Metal Catalyzed N- and C-Alkylation Reactions via Borrowing Hydrogen or Hydrogen Autotransfer. Chem. Rev. 2019, 119, 2524-2549. 